1 Drosos AA, Christou L, Galanopoulou V, Tzioufas AG Tsiakou EK. D-Pencillamine induced myasthenia gravis: clinical, serological and genetic findings. Clin Exp Rheumatol 1993; 11: 387-91.

2 Dubost J, Soubrier M, Bouchet F, et al. Neuromuscular complications of D-penicillamine in rheumatoid arthritis. Rev Neurol Paris 1992; 148: 207-11.

3 Epstein O, Jain S, Lee RG, et al. D-Pencillamine treatment 3 Epstein O, Jain S, Lee RG, et al. D-Pencillamine treatment improves survival

4 Kaplan MM. Medical treatment of primary biliary cirrhosis. In: Berk PD, Lieber CS, Schaffner F, Gershwin ME Mackay IR, eds. Primary biliary cirrhosis. Semin Liver Dis 1989; 9: $138-43$.

5 Berg PA, Klein R. Cholestatic liver diseases. In: Gitlin N, Fevery J, eds. Liver. Curr Opin Gastroenterol 1993; 9: 411 - 4 .

6 Kuncl RW, Pestronk A, Drachman DB, Rechthand E. The pathophysiology of penicillamine-induced myasthenia gravis. Ann Neurol 1986; 20: 740-4.

7 Floreani A, Caroli A, Chiaramonte M, Gasparoni P, Naccarato $R$. Hyperthyroidism associated with primary biliary cirrhosis. Two case reports. Rec Progr Med 1989; 80: 582 .
8 Nieri S, Riccardo GG, Salvadori G, Surrenti C. Primary biliary cirrhosis and Grave's disease. 7 Clin Gastroenterol 1985; 7: 434-7.

9 Roll J, Boyer JL, Barry D, Klatskin G. The prognostic importance of clinical and histologic features in asymptomatic and symptomatic primary biliary cirrhosis. $N$ Engl $f$ Med 1983; 308: $1-7$.

10 Thompson NP, Leader S, Jamieson CP, Burnham WR Burroughs AK. Reversible jaundice in primary biliary Burroughs AK. Reversible jaundice in primary biliary 106: $1342-3$.

11 Yamada G, Hyodo I, Tobe $\mathrm{K}$, et al. Ultrastructural immunocytochemical analysis of lymphocytes infiltrating bile duct epithelia in primary biliary cirrhosis. Hepatology 1986; 6: 385-91.

12 Van den Oord JJ, Sciot R, Desmet VJ. Expression of MHC products by normal and abnormal bile duct epithelium. $\mathscr{F}$ Hepatol 1986; 3: 310-7.

13 Sherlock S. Primary biliary cirrhosis and vanishing bile ducts. In: McIntyre N, Benhamou IP, Bircher J, Rizzetto M, Rodes J eds. Oxford textbook of climical hepatology. Oxford: Oxford University Press, 1991; pp 743-50.

\title{
An unusual lesion of the penis
}

\author{
M Saharay, A Farooqui, M Chappell
}

A 53-year-old uncircumcised man presented with a one-week history of a painful swelling on the ventral aspect of the corona of his penis. He had first noticed a nontender swelling in that region one month previously. He denied any urinary symptoms or urethral discharge. On examination the distal third of his penis was grossly swollen and tender, and the foreskin could not be retracted. There was no inguinal lymphadenopathy and tests for sexually transmitted diseases were negative. He was treated initially with intravenous antibiotics followed by local excision. The histology of the lesion is depicted in figure 1 .

\section{Southend General Hospital, Essex, UK Department of Surgery \\ M Saharay \\ A Farooqui \\ Department of Pathology, M Chappell}

Correspondence to Mr M Saharay, Research Fellow, UCLMS,

The Vascular Laboratory, Jules Thorn Building,

The Middlesex Hospital, Mortimer Street, London WIN8AA, UK

Accepted 24 January 1996

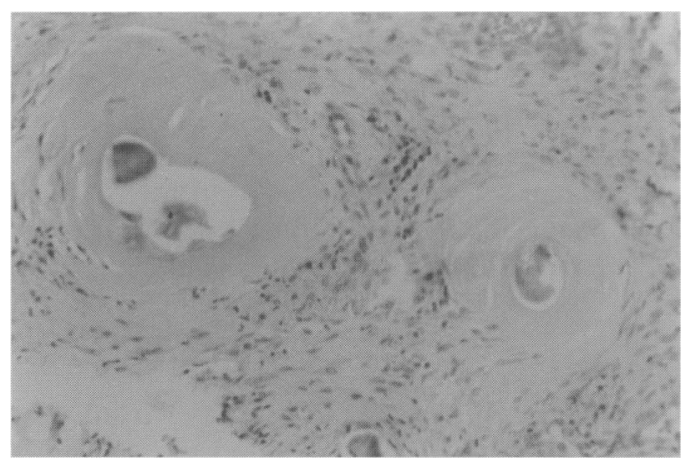

Figure 1 Haematoxylin and eosin stain

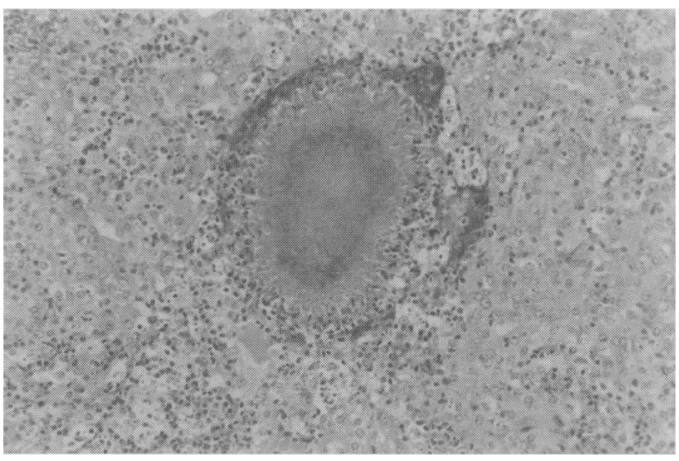

Figure 2 Periodic acid Schiff stain 


\section{Answers}

QUESTION 1

The histology shows inflammatory cells and foreign body giant cells characteristic of an abscess cavity containing hairs characterised by their stippled appearance and pigmentation with surrounding reactive fibrosis.

\section{QUESTION 2}

The diagnosis is pilonidal abscess of the penis which is due to infection in an existing pilonidal sinus. Pilonidal sinus of the penis was first described by Bervar et al in 1968 . Uncircumcised males between 20 and 60 years are affected, the commonest site being the region around the corona involving the foreskin. It is postulated that the coronal sulcus acts as a cleft where hairs may accumulate and are driven into the shaft of the penis and the prepuce by the natural movement that occurs between these two surfaces.

\section{QUESTION 3}

Actinomycosis infection has been reported to be associated with pilonidal abscess of the penis. ${ }^{2}$ In our patient, histology also showed colonies of Gram-positive organisms with brightly eosinophilic club-like structures radiating around the periphery, characteristic of actinomycosis infection (figure 2). It is caused by a branching bacteria, Actinomyces israelii, a normal commensal of the gastrointestinal tract, associated with ulcer, sinus and abscess formation and rarely systemic disease, particularly in immunocompromised patients. The organism is sensitive to penicillin.

\section{QUESTION 4}

The natal cleft is the most commonly affected site; other sites where the condition has been described include the hand, axilla, ${ }^{3}$ perineum, ${ }^{4}$ amputation sites, ${ }^{5}$ umbilicus, the suprapubic region, ${ }^{6}$ and in women the clitoris. ${ }^{7}$ It predominantly affects young, dark-haired, hirsute white males, but does also occur in blonde hairless types.

\section{Discussion}

Pilonidal sinus was first described by Anderson in $1847^{8}$ although the term was coined by Hodges in $1880 .{ }^{9}$ Most authors agree that the

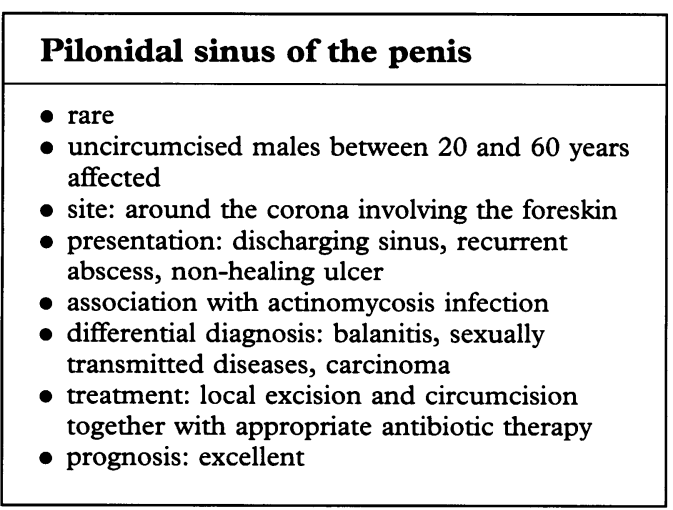

condition is acquired. The support for the acquired theory came from their occurrence in situations like the finger web in barbers, the axilla and amputation stumps, and the fact that it occurs at a later age than is expected of congenital lesions. No hair follicles can be demonstrated in the walls lining the sinus. Brearly ${ }^{10}$ postulated that the hairs burrowed into the skin by a process of twisting and drilling finally losing their follicular attachments.

Patients with pilonidal sinus of the penis commonly present with a history of discharging sinus, recurrent abscesses or a nonhealing ulcer, which may clinically mimic a neoplastic lesion. There may be a history of a previous pilonidal sinus involving another anatomical region. Inguinal lymph nodes are usually not enlarged but may be palpable due to superadded infection. Tests for sexually transmitted diseases are negative. Pilonidal abscess is an unusual cause of penile swelling and has to be differentiated from balanitis and carcinoma.

Actinomycosis associated with pilonidal sinus of the penis is extremely rare and there is only one report of this in the literature. ${ }^{2}$ In our patient a cavitated lesion measuring $3 \times 2 \mathrm{~cm}$ containing pus and hairs was excised; he would not consent to circumcision. Infection with Actinomyces was diagnosed on histology. Culture of the pus swab failed to grow any organism. The patient was commenced on long-term penicillin and the wound healed. However, his prepuce remained thickened and could only be partially retracted; circumcision was performed three months later from which he made an uneventful recovery and remains symptom free one year later.

Clinicians need to be aware of this condition occurring in patients presenting with unusual lesions on the penis and, if suspected, pus should be collected in a sterile tube (a swab is usually insufficient) and inspected in good light for the presence of pin-sized 'sulphur granules'. On microscopy the granules are seen to consist of Gram-positive mycelia. It is possible to make the diagnosis on histology alone. If diagnosed early and treated with local excision and circumcision together with long-term penicillin, the prognosis is excellent and morbidity from recurrent sepsis can be avoided.

\section{Actinomyces israelii}

- anaerobic, Gram-positive branching bacteria

- normal commensal of the mouth and gastrointestinal tract

- causes chronic inflammation and multiple loculated abscess cavities with induration and sinus formation

- common sites affected: cervicofacial (70\%), right iliac fossa (20\%), lungs (10\%)

- spread: direct contact and via bloodstream

- diagnosis: microscopy and culture of pus (characteristic 'sulphur granules' in pus)

- treatment: prolonged course of penicillin/ tetracycline/lincomycin 


\section{Final diagnosis}

Actinomycosis associated with pilonidal abscess of the penis.

1 Bervar M, Manojlovic D, Ceramilac A. Pilonidal sinus of the penis. Vojnosanit Pregl 1968; 25: 199-200 2 Rashid AM, Williams RM, Parry D, Malone PR. Actino1992; 148: 405-6.

3 Ohtsuka H, Arashiro K, Watanabe T. Pilonidal sinus of the axilla: report of five patients and review of the literature. Ann Plast Surg 1994; 33: 322-5.

4 Smith TE. Anterior or perineal pilonidal cysts. $\mathcal{F} A M A 1948$; 136: 973

Khan F, Fisher R. Pilonidal sinus in an amputee. $f$ R Army Med Corps 1991; 137: 88-9.
Keywords: actinomycosis, pilonidal cyst, penile disease

6 Patey DH, Currey RC. Pilonidal sinus presenting in the suprapubic region of a woman. Lancet 1962; 1: 620 .

7 Palmer E. Pilonidal cyst of the clitoris. Am $\mathcal{F}$ Surg 1957; 93: 133.

8 Anderson AW. Hair extracted from an ulcer. Boston Med Surg ₹ 1847; 36: 74 .

Hodges RM. Pilonidal sinus. Boston Med Surg $\mathcal{F} 1880$; 103: 485

10 Brearly R. Pilonidal sinus; a new theory of origin. Br f Surg 1955; 43: 62 .

\title{
Facial swelling in a patient with sarcoidosis
}

\author{
MJ Ledson, MC Walton, CRK Hind
}

A 50-year-old woman was referred with a six-week history of shortness of breath on exertion, and swelling of her arms and face. Thirty months earlier, an incidential chest X-ray had shown right hilar and mediastinal lymphadenopathy with clear lung fields (figure 1). She was a nonsmoker whose cousin had recently been diagnosed as having pulmonary sarcoidosis. Heaf and Kveim tests had been performed and were negative.

She was followed up for one year in which time serial chest $\mathrm{X}$-rays remained unchanged. At this point, a nasal biopsy was performed and was reported as showing 'numerous epithelioid granulomas consistent with sarcoidosis'. Once again, serial chest X-rays were performed which remained unchanged for a further 16 months. At the time of referral, she had been on prednisolone therapy ( $45 \mathrm{mg}$ daily) for eight weeks. A fine needle aspiration of a supraclavicular lymph node performed the week before referral had been 'consistent with sarcoidosis'. Her chest $\mathrm{X}$-ray on referral is shown in figure 2 .

Royal Liverpool and Broadgreen University Hospital Trust, Prescot Street, Liverpool L7 8XP, UK

MJ Ledson

MC Walton

CRK Hind

Correspondence to Dr CRK Hind

Accepted 24 January 1996

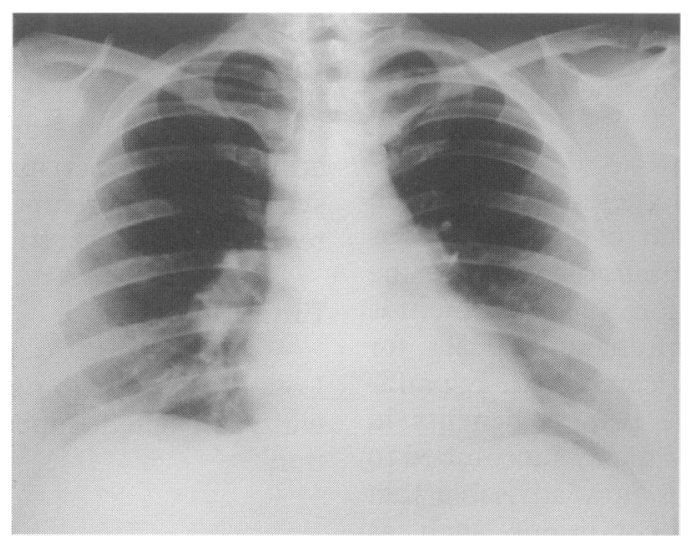

Figure 1 Chest X-ray 30 months earlier

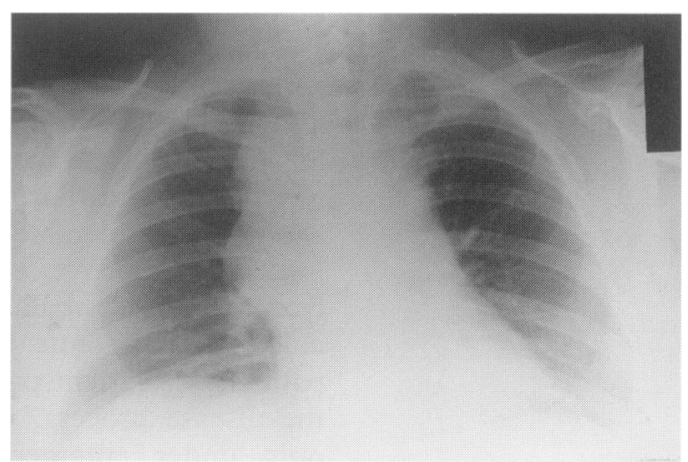

Figure 2 Chest X-ray at time of referral 